\title{
Metal-Containing Ceramic Composite with In-Situ Grown Carbon Nanotube as a Cathode Catalyst for Anion Exchange Membrane Fuel Cell and Rechargeable Zinc-Air Battery
}

Prabu Moni, Maurício Goraiebe Pollachini, Michaela Wilhelm, Julian Lorenz, Corinna Harms, M. Mangir Murshed, and Kurosch Rezwan

ACS Appl. Energy Mater., Just Accepted Manuscript • DOI: 10.1021/acsaem.9b01276 • Publication Date (Web): 17 Jul 2019

Downloaded from pubs.acs.org on July 18, 2019

\section{Just Accepted}

"Just Accepted" manuscripts have been peer-reviewed and accepted for publication. They are posted online prior to technical editing, formatting for publication and author proofing. The American Chemical Society provides "Just Accepted" as a service to the research community to expedite the dissemination of scientific material as soon as possible after acceptance. "Just Accepted" manuscripts appear in full in PDF format accompanied by an HTML abstract. "Just Accepted" manuscripts have been fully peer reviewed, but should not be considered the official version of record. They are citable by the Digital Object Identifier (DOI®). "Just Accepted" is an optional service offered to authors. Therefore, the "Just Accepted" Web site may not include all articles that will be published in the journal. After a manuscript is technically edited and formatted, it will be removed from the "Just Accepted" Web site and published as an ASAP article. Note that technical editing may introduce minor changes to the manuscript text and/or graphics which could affect content, and all legal disclaimers and ethical guidelines that apply to the journal pertain. ACS cannot be held responsible for errors or consequences arising from the use of information contained in these "Just Accepted" manuscripts. 


\title{
Metal-Containing Ceramic Composite with In-Situ Grown Carbon Nanotube as a Cathode Catalyst for Anion Exchange Membrane Fuel Cell and Rechargeable Zinc-Air Battery
}

\author{
Prabu Moni ${ }^{\mathrm{a}, \mathrm{b}}$, Maurício Goraiebe Pollachinia, c, Michaela Wilhelm*, Julian Lorenz ${ }^{\mathrm{d}}$, \\ Corinna Harms ${ }^{d}$, M. Mangir Murshede, f, Kurosch Rezwan ${ }^{\text {a, }}$ \\ ${ }^{a}$ University of Bremen, Advanced Ceramics, Am Biologischen Garten 2, IW3, Bremen, \\ Germany \\ ${ }^{\mathrm{b}}$ CSIR-Central Electrochemical Research Institute-Madras unit, CSIR Madras Complex, \\ Taramani, Chennai - 600 113, India \\ ${ }^{\mathrm{c}}$ Federal University of Santa Catarina, Department of Materials Engineering, Florianópolis - \\ SC, 88040-900, Brazil \\ ${ }^{\mathrm{d}}$ DLR Institute of Networked Energy Systems, Department Fuel Cells, 26129 Oldenburg, \\ Germany \\ ${ }^{\mathrm{e}}$ University of Bremen, Institute of Inorganic Chemistry and Crystallography, Leobener \\ Straße 7, 28359 Bremen, Germany \\ ${ }^{\mathrm{f}}$ University of Bremen, MAPEX Center for Materials and Processes, Bibliothekstraße 1, \\ 28359 Bremen, Germany \\ * Corresponding author. Tel.: +49 421218 64944; fax: +49 42121864932. \\ E-mail address: mwilhelm@uni-bremen.de
}

\begin{abstract}
The development of new air-breathing cathode catalyst not only thrust the performance of fuel cells and metal-air batteries, but also make them cheaper. Herein, we developed a new, metal containing (Ni, Co, Pt and their alloys) ceramic composite as a cathode electrocatalyst for anion exchange membrane fuel cell (AEMFC) and zinc-air battery (ZAB) application. The porous ceramic foams were generated with the help of a sacrificial template method in which polystyrene beads were infiltrated with a polysiloxane precursor. Addition of metal salts into the porous ceramic matrix the formation of carbon nanotubes (CNTs) by applying catalystassisted pyrolysis was facilitated. The in-situ grown CNTs in composite ceramic effect the charge transport and drastically improved the electrical conductivity of up to six orders in magnitude than the bare ceramics (H.A). The best performing Ni-containing ceramics (H.A.Ni) show improved oxygen reduction activity in half-cell measurements and for
\end{abstract}




\begin{abstract}
AEMFC delivered an open-circuit voltage of $0.65 \mathrm{~V}$ with a maximum power density of $\sim 10$ $\mathrm{mW} \mathrm{cm}{ }^{-2}$. In rechargeable ZAB systems, the H.A.Ni showed excellent battery performance with a specific capacitance of $490 \mathrm{mAh} \mathrm{g}^{-1}$, maximum power density of $110 \mathrm{~mW} \mathrm{~cm}{ }^{-2}$, and excellent discharge/charge cycle stability over 300 cycles. Results indicate that the presence of $\mathrm{CNT}$ and intermetallic silicides such as $\mathrm{Ni}_{2} \mathrm{Si}$ and $\mathrm{Ni}_{31} \mathrm{Si}_{12}$ tune the electrical properties and enhance the electrocatalytic activity towards oxygen. Thus, the Ni-containing ceramic material is as an excellent cathode catalyst for AEMFC and rechargeable ZAB applications.
\end{abstract}

\title{
KEYWORDS
}

Ceramic composite, sacrificial template, in-situ growth of CNT, electrocatalyst, AEMFC, $\mathrm{ZAB}$

\section{INTRODUCTION}

The fuel cells and metal-air batteries are a set of next-generation energy sectors, which seems to hold notable potential for safe and efficient way to store and convert energy. ${ }^{1-5}$ In rechargeable metal-air batteries, the oxygen evolution reaction (OER) and oxygen reduction reaction (ORR) occur on the cathode side during charge and discharge process, respectively. During ORR, the oxygen diffuses, is reduced and the produced hydroxide migrates across the electrolyte, while during OER, the process is reversed and oxygen evolves. Due to the sluggish kinetics of both ORR/OER, an electrocatalysts is highly essential to facilitate the ORR/OER reaction pathways. Hence, the electrocatalysts determines to a large extent the energy conversion or storage efficiency by reducing the overpotential for both ORR/OER and enhancing the cycle life when the reactant is in a gas phase. ${ }^{6-8}$ Until now, precious catalysts such as $\mathrm{Pt} / \mathrm{C}$ are normally applied as ORR catalyst for fuel cells and $\mathrm{Ru} / \mathrm{C}, \mathrm{Ir} / \mathrm{C}$ exhibit promising potentials for OER based electrolysis, whereas $\mathrm{Pt}-\mathrm{Ru} / \mathrm{C}$ is predominantly used as a bi-functional catalyst for metal-air batteries. However, the widespread utilization of precious catalysts is limited by their unaffordable price, the paucity of the noble metals, and poor 
durability. ${ }^{9-11}$ Current challenges in electrocatalyst research include identifying a new affordable catalyst, materials processing, understanding unprecedented properties, and use them. ${ }^{11}$

Recently, polymer-derived ceramics (PDCs) have been emerging as a prospective aspirant due to their high thermodynamic and chemical stability. However, the low electrical conductivity and poor electrocatalytic activity are the main impediment of using them as electrocatalyst. On the other hand, the possibility of tailoring the electrical and electrocatalytic properties of PDC, by different precursors, increasing the pyrolysis temperature or adding conductive fillers make them one of the suitable candidates. ${ }^{12,13}$ The in-situ growth of Carbon Nanotubes $(\mathrm{CNT})$ within a porous PDC structure was already reported with the presence of dehydrogenation-active transition metal nanoparticles by applying catalyst-assisted pyrolysis (CAP). ${ }^{14-18}$ For creating porous PDCs, various methods such as foaming, freeze-casting, or sacrificial templates were widely described. ${ }^{12,19-21}$ Previous studies in our group demonstrated that the promising way to get interconnected pore structures is by using the sacrificial template technique with polystyrene beads (expandable; $98 \mathrm{Vol} \%$ air). ${ }^{22}$ Moreover, one of the main advantages of using PDCs is that the added metal precursors can be mixed directly with the polymer precursor, which provides a homogeneous distribution of metal nanoparticles. With these special features, the PDCs were employed in many applications such as electrode for energy storage (lithium-ion batteries, sodium-ion batteries, supercapacitors) and solid adsorbents for gas adsorptions $\left(\mathrm{CO}_{2}, \mathrm{SO}_{2}\right.$ gases $) .{ }^{23-31}$ Recent studies have shown that a metalcontaining ceramic electrocatalysts act as a new class of catalysts for the ORR and OER. ${ }^{32,33}$ Very recently, cobalt particle promote the CNTs growth in mesoporous carbon has been reported for $\mathrm{Li}_{-} \mathrm{O}_{2}$ air cell applications. ${ }^{34}$ Interestingly, there have been only a few reports on transition metal silicide-based catalyst as non-noble metal-based hydrogenation catalyst due to its unprecedented physical and chemical properties. Within the transition metal silicides, the dopant Si lower the $\mathrm{d}$ band structure and modify the electronic structure around the Fermi 
level of intermetallic metal silicide which further improve the electrical conductivity as well as chemical and thermal stability. ${ }^{33,35-40}$ However, to the best of our knowledge, the use of transition metal silicide-based electrocatalysts have never been investigated for anion exchange membrane fuel cell (AEMFC) and zinc-air battery (ZAB) application. In this paper, we describe a preparation method to generate non-precious metal containing hybrid ceramic foams suitable for energy storage and conversion device. The macro porosity was realized by using polystyrene beads, which later help the formation of in-situ growth of CNT. Therefore, the main aim of this work was to ascertain if the novel materials are suitable as cathode electrocatalysts for AEMFC and ZAB.

\section{EXPERIMENTAL SECTION}

\section{Synthesis of ceramic monolith}

For the preparation of porous ceramic monolith, the sacrificial template method followed by catalyst-assisted pyrolysis was used. ${ }^{22}$ In this preparation process, a silicone resin poly (methyl phenyl silsesquioxane) (Silres ${ }^{\circledR} H 44, \quad$ WackerChemie AG) and 3aminopropyltriethoxysilane (APTES, ABCR, Germany) were used as components of the polymeric precursors. Expanded polystyrene beads (PSB, $0.5-1 \mathrm{~mm}$, Fa. Klassen Vitali, Germany) consisting of 98 vol $\%$ air and 2 vol\% polystyrene was used as sacrificial templates. The metal salt such as nickel chloride $\left(\mathrm{NiCl}_{2}\right)$, cobalt chloride $\left(\mathrm{CoCl}_{2}\right)$, and chloroplatinic acid $\left(\mathrm{H}_{2} \mathrm{PtCl}_{6} \cdot 6 \mathrm{H}_{2} \mathrm{O}\right)$ was used as metal source. The calculated amount of H44, APTES and metal salt were separately mixed with ethanol and stirred for 3 hours to ensure a complete dissolution. The molar ratios of H44 : APTES and APTES : metal salt were optimized in a previous study and values of $92: 8$ and $8: 1$ respectively, were used. ${ }^{22}$ After the complete dissolution of each set, these solutions were mixed together and stirred. The sacrificial templates (polystyrene beads) were filled in a medical syringe based on a volume compression and dimension of the sample. Then the metal salt-containing polymer solution 
was infiltrated into the medical syringe and compress by $6.25 \%$ of the volume. ${ }^{22}$ This compression was chosen since it allows for achieving a porous structure. After three days of cross-linking at room temperature, the samples were taken out from the syringe and thermally cross-linked at $100{ }^{\circ} \mathrm{C}$ for $24 \mathrm{~h}$ followed by final pyrolysis at $1000{ }^{\circ} \mathrm{C}$ for $4 \mathrm{~h}$ in an atmosphere of nitrogen. The samples were named as H.A, H.A.Ni, H.A.Co, H.A.Pt, H.A.Ni.Co, H.A.Ni.Pt, and H.A.Co.Pt respectively, whereas the letter $\mathrm{H}$ stands for poly (methyl phenyl silsesquioxane), A for APTES, Ni for nickel, Co for cobalt, and Pt for platinum precursors. Detailed synthesis procedure and schematic view of a monolithic structure were presented in Fig. S1, S2 (Supporting Information) and Table S1 (SI).

\section{Material characterization}

X-ray diffraction pattern of the ceramic composite was obtained by using a Seifert XRD powder diffractometer ( $\mathrm{Cu}-\mathrm{K} \alpha$ radiation, ID 3303, General Electric, USA). Raman spectra were recorded on a LabRAM ARAMIS (Horiba Jobin Yvon) with a laser working at $633 \mathrm{~nm}$ with less than $20 \mathrm{~mW}$. The decomposition behaviour of ceramic precursors was measured with a thermogravimetric analyzer (STA 503 BÄHR). The surface morphology, CNT formation and metal particle distributions were investigated with the help of FESEM (ZEISS Supra 40, Oberkochen, Germany) and FETEM (FEI Titan 80, 300 kV) respectively. The specific surface area and pore size distribution of ceramic composite was calculated by using nitrogen adsorption/desorption isotherms with a Belsorp-Max (Bel Japan Inc.) and mercury intrusion porosimetry (Pascal 140/440 POROTEC GmbH) respectively. For conductivity measurements, AC impedance studies were carried out with ceramic pellets $(\approx 1$ $\mathrm{mm}$ of thickness and $10 \mathrm{~mm}$ diameter) using stainless steel as blocking electrodes and a computer-controlled electrochemical analyzer (IM6ex Zahner ${ }^{\circledR}$ Elektrik) in the frequency range of $1 \mathrm{MHz}$ to $10 \mathrm{mHz}$ at room temperature. 


\section{Electrocatalytic measurements}

The bi-functional activities (ORR/OER) of ceramic catalyst were tested with a help of computer-controlled electrochemical workstation (Biologic, VSP/VMP 3B-20, France) interfaced with a rotating ring-disk electrode apparatus (RRDE-3A) using the linear sweep voltammetry and cyclic voltammetry (LSV \& CV) method. The specific electrocatalytic characterization details were reported in the previous literature. ${ }^{33}$ A platinum wire, saturated calomel electrode and catalyst coated glassy carbon were acted as the counter, reference and working electrodes, respectively. The catalyst inks were prepared by suspending $3.55 \mathrm{mg}$ ceramic catalyst into a mixture of $150 \mu \mathrm{L}$ of DI water, $250 \mu \mathrm{L}$ ethanol and $10 \mu \mathrm{L} 5 \mathrm{wt} \%$ Nafion ionomer solution. A homogenous coating of catalyst ink was achieved by pipetting 4 $\mu \mathrm{L}$ ink on a glassy carbon disc electrode to obtain a loading of $500 \mu \mathrm{g} \mathrm{cm} \mathrm{cm}^{-2}$ and electrocatalytic activities were tested in $0.1 \mathrm{M} \mathrm{KOH}$ electrolyte solution under oxygen saturated condition (before $\mathrm{N}_{2}$ saturated electrolyte was used for background correction). State of the art ORR catalyst Pt/C (40\%) with the loading of $60 \mu \mathrm{g} / \mathrm{cm}^{2}$ and OER catalyst $\mathrm{RuO}_{2}$ with the loading of $500 \mu \mathrm{g} / \mathrm{cm}^{2}$ were also tested for reference.

\section{AEMFC assembly and testing}

In the AEMFC, the commercial gas diffusion layer (GDL, SGL DC-35) was used as a backing layer for both anode and cathode. The cathode catalyst ink was prepared by dispersing $8 \mathrm{mg}$ of the ceramic composite in $0.8 \mathrm{mg}$ of $10 \mathrm{wt} \%$ Fumion FAA-3 ionomer and suitable amount of solvent under ultrasonication. Then the catalyst ink was coated on the GDL using brush coating technique with the catalyst loading of $2 \mathrm{mg} \mathrm{cm}^{-2}$. The anode was prepared by coating of a commercial Pt/C (40\%) on a GDL with a loading of $0.5 \mathrm{mg} \mathrm{cm}$. Both electrodes were immersed in $1 \mathrm{M} \mathrm{KOH}$ solution for 12 hours to replace the $\mathrm{Br}^{-}$ions by $\mathrm{OH}^{-}$ions. The commercial Fumapem membrane (FumaTech) with a thickness of $50 \mu \mathrm{m}$ was 
used as membrane after immersed in $2 \mathrm{M} \mathrm{KOH}$ solution for 12 hours to replace the existing $\mathrm{Cl}^{-}$ions by $\mathrm{OH}^{-}$ions at room temperature. ${ }^{41,42}$ Fuel cell was constructed by in-situ assembly of a membrane sandwiched between the cathode $\left(4 \mathrm{~cm}^{2}\right.$ active area) and anode in a commercially available fuel cell hardware (Fuel cell Tech. Inc., USA) with parallel serpentine flow field machined on graphite plates. During the measurements, the reactants $\mathrm{H}_{2}$ and $\mathrm{O}_{2}$ with $100 \%$ relative humidity $(\mathrm{RH})$ were fed into the anode and cathode side at a flow rate of 100 and $150 \mathrm{~mL} \mathrm{~min}^{-1}$, respectively. The galvanostatic polarization studies were conducted using LCN 100-36 electronic loads from Bitrode Corporation, USA.

\section{$\mathrm{ZAB}$ assembly and testing}

The ceramic catalyst containing ZAB was assembled in a homemade setup (Fig. S3). In a typical procedure, catalyst ink was prepared by dispersing $6 \mathrm{mg}$ of ceramic catalyst in 12 $\mathrm{mg}$ of $5 \mathrm{wt} \%$ Nafion ionomer and suitable amount of ethanol under constant ultrasonication. Then the catalyst ink was coated on the GDL (SGL DC-35) by using brush coating technique with a catalyst loading of $1 \mathrm{mg} \mathrm{cm}$, which is explored as cathode. A polished zinc plate, polypropylene (PP) membrane, and $6 \mathrm{M} \mathrm{KOH}$ alkaline solution were used as the anode, separator and electrolyte, respectively. Before constructing the cell, the polypropylene separator was immersed in electrolyte solution for 12 hours to enrich $\mathrm{OH}^{-}$ions. In-situ assembly of electrolyte-enriched separator sandwiched between the zinc-plate and catalystcoated GDL, can assemble ZAB can be assembled. The galvanostatic response of ZAB was performed by consuming air from the environment by using an electrochemical workstation (Biologic, VSP/VMP 3B-20, France). The specific capacity of primary ZAB was calculated based on the mass of zinc consumed during discharge. Polarization and power density curves of the ZAB were analyzed by using LCN100-36 electronic loads from Bitrode CorporationUSA, by feeding air from the environment at room temperature and ambient pressure. 


\section{RESULTS AND DISCUSSION}

\section{Structure and morphology}

To produce porous ceramic monoliths, the sacrificial template method is the promising way to get foam structures with interconnected pores, which are essential for catalytic supports used in fuel cells and metal-air battery, where the reactant is in the gas phase. The addition of a metal salt into a ceramic matrix result in a formation of electrocatalytically active species with the help of catalyst-assisted pyrolysis. The XRD pattern of bare (H.A) and metal-containing ceramics (H.A.Ni and H.A.Co) pyrolyzed at $1000{ }^{\circ} \mathrm{C}$ are shown in Fig. 1a. The bare H.A shows the typical H44 non-crystalline ceramic structure with two broad halos at 23 and $43^{\circ}$. The metal-containing ceramics show a strong diffraction peak at $26.2^{\circ}$ related to graphitic carbon phase and not showing any $\mathrm{H} 44$ peaks. ${ }^{15}$ In addition to these observations, the Ni-containing ceramics show the reflexes of intermetallic nickel silicide such as $\mathrm{Ni}_{2} \mathrm{Si}$ and $\mathrm{Ni}_{31} \mathrm{Si}_{12} \cdot{ }^{33}$ For Ni-containing ceramics even at $1000{ }^{\circ} \mathrm{C}$, the Ni strongly favors the reduction of Si-O bonds and the forthright formation of nickel silicides. When the pyrolysis temperature increases, the diffusion rate of the $\mathrm{Si}$ atom into metallic Ni gradually increases, the dopant $\mathrm{Si}$ modify the metal coordination in nickel silicides, leading to a downshift of the $\mathrm{d}$ band center and a strong alteration of the electronic structure nearby the Fermi level. ${ }^{37,39,40}$ At $1000{ }^{\circ} \mathrm{C}$ the small amount of $\mathrm{Si}$ atoms distributed into the nickel rich lattice results in a mixture of $\mathrm{Ni}_{2} \mathrm{Si} / \mathrm{Ni}_{31} \mathrm{Si}_{12}$ with $28-33$ at $\% \mathrm{Si}^{40,43}$ However, in case of cobalt-containing ceramics, only the diffraction peaks of metallic cobalt particles are found. The formation of intermetallic cobalt silicide is rather hindered at $1000{ }^{\circ} \mathrm{C}$, since a further increase in temperature would be required for reduction of $\mathrm{Si}-\mathrm{O}$ bonds and the formation of intermetallic cobalt silicides. ${ }^{40}$ Thus, the interaction between the Co and $\mathrm{Si}$ is somewhat limited, what causes a lower weight loss (Fig. S4). The XRD patterns of H.A.Pt, H.A.Ni.Pt and H.A.Co.Pt was almost similar to that of bare H44, indicating the non-crystalline nature (Fig. S5a). Whereas Pt-containing 
ceramics shows few peaks of intermetallic platinum silicide $\left(\mathrm{Pt}_{2} \mathrm{Si}\right)$. Hence, the addition of $\mathrm{Pt}$ and its alloys did not influence the formation of graphitic carbon. Apart from crystallinity, the ordered/disordered nature of carbon present in the ceramic matrix was investigated with the help of Raman spectroscopy (Fig. 1b, Fig. S5b). ${ }^{44}$ All ceramics show the first order sharp peak at $\sim 1332 \mathrm{~cm}^{-1}$ assigned as D peak caused by the disordered structure of the graphite structure in the ceramic matrix. The presence of $E_{2 g}$ mode peak at $\sim 1595 \mathrm{~cm}^{-1}$ assigned as $\mathrm{G}$ peak is due to the in-plane bond stretching of $\mathrm{sp}^{2}$ carbon atoms within the ceramic composite. An increase in $\mathrm{I}_{\mathrm{G}} / \mathrm{I}_{\mathrm{D}}$ intensity ratio observed for PDC with the addition of $\mathrm{Ni}$, Co, Ni-Pt and Co-Pt confirm the presence of curved and closed graphitic structures in nanotubes forms. ${ }^{45} \mathrm{In}$ addition, the strong appearance of a $2 \mathrm{D}$ peak at $\sim 2673 \mathrm{~cm}^{-1}$ for $\mathrm{Ni}, \mathrm{Co}, \mathrm{Ni}-\mathrm{Pt}$, and $\mathrm{Co}-\mathrm{Pt}$ containing ceramics shows the existence of graphene layer confirming the higher degree of CNT formation. ${ }^{46-48}$

In this sacrificial template method, the polystyrene beads were completely dispersed in a continuous polymeric solution. During the thermal process, the complete removal polystyrene beads create a foam type monolithic structure (Fig. S4). ${ }^{22}$ Fig. 2 shows the FESEM images of bare (H.A) and metal-containing ceramics pyrolyzed at $1000^{\circ} \mathrm{C}$. The ceramic monolith shows a foam type structure with interconnected spherical cells having diameters in the range of $0.5-$ $1.0 \mathrm{~mm}$. The regular arrangement of polystyrene beads in the mold and optimal compression (6.25\% vol.) applied during the process helps the beads to easily deform and produces spherical, interconnected macropores in each side of the monolith (Fig. S6). It is already reported that in catalyst-assisted pyrolysis the in-situ growth of CNT is possible in porous PDC, with the help of a metal catalyst. ${ }^{15,16,43,49}$ The metal (Ni and Co)-containing ceramics pyrolyzed at $800{ }^{\circ} \mathrm{C}$ show the beginning of $\mathrm{CNT}$ formation in pores and formation is more pronounced when the pyrolysis temperature increased to $1000{ }^{\circ} \mathrm{C}$ (Fig. 2(c-e), Fig. S7). However, in the case of bare H.A, the formation of CNTs at both temperatures cannot be observed (Fig. 2(a, b), Fig. S7). The formation of CNTs in Ni/-Co containing PDC is 
facilitated by various factors:15,16 (i) the metal-containing ceramics show a decrease in activation energy for soot oxidation as a result of metal (intermediate oxide) transfers oxygen to soot particles; (ii) the electronic interaction between $\pi$ state of carbon atoms $\left(\mathrm{sp}^{2}\right)$ with the metal or metal oxide leads to a less delocalized electronic state of carbon atoms due to higher electronegativity of carbon (2.55) compared with transition metal (Ni (1.91); Co (1.88)); and (iii) the addition of $\mathrm{Ni} /-\mathrm{Co}$ based catalyst facilitate the dehydrogenation reaction that involves the removal of hydrogen from a PDC. These possible mechanisms for the formation of CNTs in metal-containing PDC have been presumed from similar material described in various literature. ${ }^{15,16,50,51}$ Moreover, the reaction started at gas phase promotes the in-situ growth of CNTs, whereas in the solid matrix results in turbostratic carbon. ${ }^{43}$ The grown CNTs show at least 13-15 layers (MWCNTs) with inner and outer diameters of 10-15 and 30-60 nm, respectively, with a length of a few microns (Fig. 2-4). The FETEM image shows that the intermetallic silicide's or metal nanoparticles were nicely embedded in the ceramic matrix with an average particle size of about $\sim 20 \mathrm{~nm}$ (Fig. 3(a, c)). ${ }^{43}$ The EDX spectrum confirms the high atomic percentage of carbon about $69 \%$ for H.A.Ni when compared with bare H.A (31.6 \%) (Fig. S8, S9). In addition, the ceramic samples with Ni-Co alloys (H.A.Ni.Co) still show the formation of CNTs (Fig. 4(a, b)). However, the Pt-containing ceramics (H.A.Pt) did not show any formation of CNTs, instead agglomerated carbon particles are observed along with intermetallic platinum silicide spheres (Fig. 2f). The possible reasons for hampering CNT formation in Pt-based precursors at $1000{ }^{\circ} \mathrm{C}$ is due to (i) the higher activation energy for soot oxidation as a result of limited interaction of Pt with subsurface "oxide" formation at this temperature and there is no oxygen transfers to soot particles; and (ii) the electronegativity of Pt (2.28) is very similar to carbon atoms (2.55), which affects the delocalized electronic state of carbon atoms. These tentative hypothesis have been deduced from previous studies of Ni/Co-containing PDC materials. ${ }^{15,16,50,51}$ It is believed that further studies are necessary to explain the role of Pt catalyst in the oxidation process. Interestingly, the Ni-Pt (H.A.Ni.Pt) and 
Co-Pt (H.A.Co.Pt) containing ceramics possess a jellyfish-like morphology (Fig. 4(c-f)). The EDX mapping analysis at various spots of jellyfish like morphology (H.A.Ni.Pt) shows the presence of $\mathrm{Si}, \mathrm{Ni}, \mathrm{Pt}$ and oxygen in the core and carbon at the shell, ensuring that the formation of spherical Pt-Ni-Si alloys at the solid matrix and CNTs at gas phase (Fig. S10). The Ni-Pt and Co-Pt ceramic samples having various metals such as nickel, cobalt and platinum having different electronegativity, dehydrogenation properties and surface "oxide" results in a jellyfish-like morphology. Overall, the surface morphology analysis confirms that with the existence of pores in PDC the addition of $\mathrm{Ni}$ and $\mathrm{Co}$ was beneficial for an in-situ growth of CNTs.

Moreover, the thermal stability of the metal-containing ceramics is slightly better than that of bare H.A as a result of in-situ grown CNT, which improve the overall thermal stability of the ceramic composite (Fig. S4). ${ }^{52}$ The in-situ grown CNTs influence the BET specific surface and open porosity were shown in Fig. S12. The bare ceramic (H.A) sample show a Type II isotherm with negligible $\mathrm{N}_{2}$ adsorption and SSA value as close as $2 \mathrm{~m}^{2} \mathrm{~g}^{-1}$. The metal (Ni/Co)-containing ceramic composite show a Type IV hysteresis with a loop starting at lower relative pressures $\left(\mathrm{p} / \mathrm{p}_{\mathrm{o}} \sim 0.45\right)$. The Ni-containing ceramic samples show the highest open porosity $22 \%$ (calculated from mercury intrusion porosimetry) and SSA of $9 \mathrm{~m}^{2} \mathrm{~g}^{-1}$ (calculated from $\mathrm{N}_{2}$ adsorption), respectively. The existence of mesopores result from spaces between the in-situ grown CNT and the cell walls. ${ }^{14}$

\section{Electrical conductivity}

The grown CNT influences the electrical properties of ceramic composite was analyzed by applying an AC (alternate current) impedance technique. From the conductance spectrum (Fig. 5a), it is evident that at low frequencies, conductivity shows a frequencyindependent trend, what describes the DC (direct current) conductivity of the material. When the frequency increases the conductivity exhibits $\mathrm{AC}$ conductivity behavior. ${ }^{53}$ For the bare 
ceramics (H.A) at lower frequency region $(100 \mathrm{~Hz})$, the DC conductive behavior changes to $\mathrm{AC}$ conductivity and then $\mathrm{AC}$ dispersion pattern observed describing the semiconducting behavior of H.A. However, for Pt or Co-containing ceramics the frequency where the DC conductivity changing to $\mathrm{AC}$ conductivity is shifting at very high frequency $(1 \mathrm{MHz})$ and for Ni-containing ceramics the shifting region almost disappears due to the highly conductive nature of the ceramics (Fig. 5a). Fig. 5b shows the DC conductivity $\left(\sigma_{\mathrm{DC}}\right)$ of ceramic composite calculated at room temperature. Pure H.A pyrolyzed at $1000{ }^{\circ} \mathrm{C}$ shows the $\sigma_{\mathrm{DC}}$ value of $5 \times 10^{-10} \mathrm{~S} \mathrm{~cm}^{-1}$. For the metal-containing ceramics, the $\sigma_{\mathrm{DC}}$ values increase by three to six orders of magnitude. The highest conductivity value of $4.9 \times 10^{-4} \mathrm{~S} \mathrm{~cm}^{-1}$ was observed for Ni-containing ceramics and it was found to be almost one order higher than Co-containing ceramics $\left(4.4 \times 10^{-5} \mathrm{~S} \mathrm{~cm}^{-1}\right)$ due to a prominent growth of CNTs. ${ }^{52}$ Further, during the formation of intermetallic nickel silicide, the dopant $\mathrm{Si}$ modifies the electronic structure around the Fermi level of intermetallic silicide that further improve the electrical conductivity of the ceramic composite. For Pt-containing ceramics, the value drops to $2.5 \times 10^{-6} \mathrm{~S} \mathrm{~cm}^{-1}$, since the addition of Pt did not show any CNT formation at $1000^{\circ} \mathrm{C}$. In addition, the Pt-based bimetallic ceramics still show a drop in conductivity due to the limited formation of the CNT. The earlier studies showed that the electrical conductivity of Graphene or CNT incorporated H.A are still unsatisfying specifically in terms of their low electrical conductivity $\left(\sim 10^{-5} \mathrm{~S} \mathrm{~cm}^{-}\right.$ ${ }^{1}$ even after $10 \mathrm{wt} \%$ nanofillers incorporation) because of their agglomeration issues, which eventually hinders their conductivity. ${ }^{52}$ However, the Ni-containing ceramics shows the highest electrical conductivity because of in-situ grown CNT, which are uniformly embedded into the ceramic matrix.

\section{Electrocatalytic activity}

The bi-functional activity of metal-containing ceramic catalyst towards both ORR and OER was assessed by using a CV and LSV technique in alkaline media (Fig. 6 and Fig. S12- 
S13). The effect of various metal-containing ceramic catalysts on electrochemical activity is investigated (Fig. S12-S13) which clearly indicates that the Ni and Co-containing ceramics shows better electrochemical activity due to its prominent growth of conductive CNTs and formation of catalytic active intermetallic silicides. The $\mathrm{CV}$ graph of best performing H.A.Ni exhibits a well-defined oxygen reduction peak in the $\mathrm{O}_{2}$-saturated electrolyte, whereas no such peak was observed in $\mathrm{N}_{2}$-saturated electrolyte, suggesting their noticeable ORR activity (Fig. 6a). To investigate the detailed ORR reaction kinetics, LSV analysis was measured at various rotation speeds from 400 to $2500 \mathrm{rpm}$. The ORR polarization curves of $\mathrm{Ni}$ and $\mathrm{Co}-$ containing ceramic catalyst were shown in Fig. $\mathbf{6}(\mathbf{b}, \mathbf{c})$. Among all, the H.A.Ni exhibits the highest activity with an onset potential of $0.8 \mathrm{~V}$, a half-wave potential of $0.58 \mathrm{~V}$, and a limiting current density of $3.6 \mathrm{~mA} \mathrm{~cm} \mathrm{~cm}^{-2}$ respectively at $1600 \mathrm{rpm}$ in the ORR region, indicating improved ORR kinetics compared to H.A.Co. The average number of electrons (n) involved in ORR calculated from K-L plots for H.A.Ni is 3.2, which is higher than that of H.A.Co, confirming that ORR proceeds via the mixed $2^{-}$and $4^{-}$electron pathway. As for OER activity, H.A.Ni exhibits a sharp increase in current density and generates a current density of $10 \mathrm{~mA} \mathrm{~cm}{ }^{-2}$ at a potential of $1.78 \mathrm{~V}$ as shown in Fig. 6d. This result strongly suggests the superior OER activity observed for H.A.Ni compared to Co-containing ceramics. Additionally, the comprehensive bi-functional oxygen activity of the ceramic catalyst was calculated by the potential difference between the region where OER current density reaches $10 \mathrm{~mA} \mathrm{~cm}{ }^{-2}$ and ORR half-wave potential $\left(\Delta \mathrm{E}=\mathrm{E}_{\mathrm{j}=10}-\mathrm{E}_{1 / 2}\right) .{ }^{54-56}$ As shown in Fig. 6d, the H.A.Ni show the lowest $\Delta \mathrm{E}$ value of $1.20 \mathrm{~V}$, indicating a much improved bi-functional activity toward both ORR and OER. All results highlight that the importance of Ni-containing ceramics with the synergistic effect of intermetallic nickel silicides $\left(\mathrm{Ni}_{2} \mathrm{Si}\right.$ and $\left.\mathrm{Ni}_{31} \mathrm{Si}_{12}\right)$ and in-situ grown CNT, accounting for the improvement in bi-functional activity. Considering the structures of $\mathrm{Ni}_{2} \mathrm{Si}$ and $\mathrm{Ni}_{31} \mathrm{Si}_{12}$, as reflected in $\mathrm{XRD}$, it is assumed that the intermetallic nickel silicides may play a significant role in promoting the ORR/-OER activity of the Ni- 
incorporated ceramic catalyst. Moreover, it is believed from the previous studies, the presence of intermetallic silicide could improve the catalytic activity, due to its optimum adsorption energy with reaction intermediates of oxygen during both ORR/-OER. ${ }^{33}$ Further in-situ grown CNT embedded in ceramic matrix boosts the electron/ion transport. Even though the Nicontaining ceramics still show a moderate ORR activity compared with $\mathrm{Pt} / \mathrm{C}$, and OER activity compared with $\mathrm{RuO}_{2}$, but as a bi-functional catalyst it outperforms the state-of the art $\mathrm{Pt} / \mathrm{C}$ and $\mathrm{RuO}_{2}$.

\section{AEMFC analysis}

Considering the noticeable ORR activity in alkaline media, the best-performing metalcontaining ceramic catalyst was further predestinated as cathode catalyst in AEMFC. The AEMFC was constructed with the help of H.A.Ni and H.A.Co, and polarization studies were conducted by using $\mathrm{H}_{2}$ and $\mathrm{O}_{2}$ as reactants at ambient temperature and pressure (Fig. 7). As for AEMFCs activity, the H.A.Ni shows an open-circuit voltage (OCV) of $0.65 \mathrm{~V}$ and a maximum power density of $\sim 10 \mathrm{~mW} \mathrm{~cm}^{-2}$ that is superior to the Co-containing ceramics. As anticipated, the Ni-containing ceramic catalyst show improved fuel cell performance due to the synergistic effect between intermetallic nickel silicide and grown nanostructured CNT. The AEMFC performance of various non-precious catalysts were summarized in Table $\mathbf{S 2}$. Although the AEMFC performance of the Ni-containing ceramic catalyst is less than that of recently reported values, it is still comparable under similar condition using commercial Fumapem membrane (FumaTech). ${ }^{41,42,57,58}$ However, the AEMFC performance of these materials will be tested with suitable membranes for realistic performance.

\section{ZAB analysis}

Finally, the feasibility of the metal-containing ceramic air cathode is demonstrated in a homemade ZAB setup and its performance was tested by breathing open-air as a fuel. Fig. 8a 
displays the polarization and power density curves with best performing H.A.Ni and H.A.Co as cathode catalyst. The polarization profiles reveal that H.A.Ni shows an OCV of $1.48 \mathrm{~V}$ and a maximum discharge power density of $110 \mathrm{~mW} \mathrm{~cm}^{-2}$ when the current density reaches 150 $\mathrm{mA} \mathrm{cm}{ }^{-2}$. In contrast, Co-containing ceramics show an OCV of $1.41 \mathrm{~V}$ and a maximum discharge power density of $71 \mathrm{~mW} \mathrm{~cm}^{-2}$ at a current density of $125 \mathrm{~mA} \mathrm{~cm} \mathrm{c}^{-2}$. A maximum power density of $110 \mathrm{~mW} \mathrm{~cm}{ }^{-2}$ is observed for H.A.Ni, which is much higher than the benchmark $\mathrm{Pt} / \mathrm{C}+\mathrm{Ir} / \mathrm{C}$ catalyst (power density of $90.6 \mathrm{~mW} \mathrm{~cm}{ }^{-2}$ ) reported in the literature. ${ }^{59,60}$ The primary ZAB was tested by galvanostatically discharging at a constant current density of $2 \mathrm{~mA} \mathrm{~cm}{ }^{-2}$ until the voltage reaches $0.5 \mathrm{~V}$. During the deep discharge, H.A.Ni displays an excellent performance without any voltage fading over $30 \mathrm{~h}$, and delivering a specific capacity of $490 \mathrm{mAh} \mathrm{g}^{-1}$ (Fig. 8(b, c)). These results clearly confirm the excellent ORR activity of H.A.Ni in a ZAB is possibly due to the active sites of intermetallic nickel silicides in the alkaline media, which promotes the excellent ORR reaction kinetics. ${ }^{33}$ For the realization of electrically rechargeable metal-air batteries, the H.A.Ni based ZAB was galvanostatically cycled at a constant current density of $2 \mathrm{~mA} \mathrm{~cm}^{-2}$ with a 10 -min cycle period (Fig. 8d \& Fig. S14). The H.A.Ni affords an initial discharge and charge voltage of $1.26 \mathrm{~V}$ and $2.04 \mathrm{~V}$ respectively, with a voltage gap of $0.78 \mathrm{~V}$, which slightly changed to 1.23 $\mathrm{V}$ and $2.02 \mathrm{~V}$ with a voltage gap of $0.79 \mathrm{~V}$ after 300 cycles. The round-trip voltaic efficiency of H.A.Ni was calculated to be $62 \%$ of the first cycle and maintained at $61 \%$ over 300 cycles. Hence, the voltage gap of Ni-containing ZAB increases only $10 \mathrm{mV}$ after 300 cycles, which confirms the excellent long-term cycling stability. Further, to investigate the C-rate aspects, the ZAB was discharged at various current rates $\left(2-40 \mathrm{~mA} \mathrm{~cm}{ }^{-2}\right)$. The discharge potential plateau of H.A.Ni shifts downstream as the discharge current rate increases because of low ORR reaction kinetics. However, the discharge plateau remains stable for each current density applied and maintains the voltage plateau of $1.13,0.98,0.87$ and $0.66 \mathrm{~V}$ for the current density of 5, 10, 20 and $40 \mathrm{~mA} \mathrm{~cm}^{-2}$ respectively. Even after high discharge rate, 
during current step-up, the voltage plateau almost remains the same compared with the initial current step-down process (Fig. 8e). Hence at a higher current rate, the Ni-containing ceramic catalyst maintain the voltage plateau without any potential drop or damage indicating the better electrocatalytic activity and improved mass transfer efficiency. ${ }^{61,62}$ The ZAB performance of the Ni-containing ceramic catalyst is comparable to that of recently reported non-precious catalysts for ZAB and values were summarized in Table S3. Overall, the Nicontaining ceramics are not only showing high energy density and power density, but also show better rechargeability and battery's rate performance is possibly due to following aspects: i) the structure conversion from non-crystalline H44 structure to graphitic carbon phase within the ceramic structure, which enhance the chemical and thermal stability of the ceramic composite; ii) the in-situ grown CNT embedded into the ceramic matrix can provide efficient electron/ion transportation pathways and improves the overall electrical conductivity; iii) the presence of intermetallic nickel silicides $\left(\mathrm{Ni}_{2} \mathrm{Si}\right.$ and $\left.\mathrm{Ni}_{31} \mathrm{Si}_{12}\right)$ with favorable electronic structure can effectively enhance the electrocatalytic activity of ceramic composites towards oxygen. With further improvements in the synthesis route, we believe this metal-containing PDC could be used as a next generation non-precious electrocatalyst for AEMFC and ZAB applications. 


\title{
CONCLUSION
}

In summary, new cost-effective metal-containing PDCs as an air-breathing cathode catalyst for AEMFC and ZAB applications are reported. The metal-containing ceramic monoliths were generated with the help of polystyrene beads as sacrificial templates. Due to its porous foam architecture and with the help of a catalyst-assisted pyrolysis, the addition of metal salt facilitates the in-situ growth of CNTs, which further enhances the electrical conductivity by six orders of magnitude. The Ni-containing ceramics outperform other metalbased ceramic catalyst and show the better bi-functional (ORR and OER) catalytic activities. Notably, the presence of intermetallic nickel silicides $\left(\mathrm{Ni}_{2} \mathrm{Si}\right.$ and $\left.\mathrm{Ni}_{31} \mathrm{Si}_{12}\right)$ effectively enhances the electrocatalytic activity towards oxygen. As a result, the cathode catalyst in AEMFC delivers a peak power density of $\sim 10 \mathrm{~mW} \mathrm{~cm}^{-2}$ under ambient condition. Moreover, as a cathode catalyst in primary ZAB it delivers a high specific capacitance of $490 \mathrm{mAh} \mathrm{g}^{-1}$, and the maximum power density of $110 \mathrm{~mW} \mathrm{~cm}^{-2}$, respectively. For rechargeable ZAB, the H.A.Ni exhibits small discharge/charge voltage gap, better rechargeability and stable rate performance by consuming open air from the atmosphere. Most importantly, this work highlights the importance of metal-containing PDCs, which could shed light on the development of non-precious cathode catalyst for next-generation AEMFCs and ZABs.

\begin{abstract}
ASSOCIATED CONTENT
Supporting Information

The Supporting Information is available free of charge on the ACS Publications website at http://dx.doi.org/ Sample variation, Process scheme, Schematic view, TGA, XRD, Raman spectrum, FESEM, EDS, $\mathrm{N}_{2}$ adsorption-desorption isotherms, mercury intrusion porosimetry, electrocatalytic ORR-OER results, schematic view of home-made ZAB set-up, rechargeable ZAB performance, AEMFC and ZAB performance of reported catalyst comparison.
\end{abstract}




\section{AUTHOR INFORMATION}

\section{Corresponding Author}

Michaela Wilhelm *E-mail: mwilhelm@uni-bremen.de

\section{ORCID}

Prabu Moni

Maurício Goraiebe Pollachini

Julian Behnken:

Michaela Wilhelm:

M. Mangir Murshed:

Kurosch Rezwan:
0000-0003-2389-5292

$\underline{0000-0003-1772-5086}$

0000-0002-9936-7667

$\underline{0000-0001-8651-1546}$

$\underline{0000-0002-9063-372 X}$

$\underline{0000-0002-7318-1119}$

\section{Notes}

The authors declare no competing financial interest.

\section{ACKNOWLEDGEMENTS}

This research work was supported by Deutsche Forschungsgemeinschaft (DFG) within the Research Training Group GRK 1860 “Micro-, meso- and macroporous nonmetallic Materials: Fundamentals and Applications" (MIMENIMA). One of the authors, Dr. Prabu Moni grateful to the Department of Science and Technology (DST), New Delhi, India for awarding INSPIRE Faculty Award (DST/INSPIRE/04/2016/000530). 


\section{REFERENCES}

(1) Huang, Y.; Zhu, M.; Huang, Y.; Pei, Z.; Li, H.; Wang, Z.; Xue, Q.; Zhi, C. Multifunctional Energy Storage and Conversion Devices. Adv. Mater. 2016, 28 (38), 8344-8364.

(2) Li, Y.; Lu, J. Metal-Air Batteries: Will They Be the Future Electrochemical Energy Storage Device of Choice? ACS Energy Lett. 2017, 2 (6), 1370-1377.

(3) Clark, S.; Latz, A.; Horstmann, B. A Review of Model-Based Design Tools for MetalAir Batteries. Batteries 2018, 4 (1), 5.

(4) Gröger, O.; Gasteiger, H. A.; Suchsland, J.-P. Review-Electromobility: Batteries or Fuel Cells? J. Electrochem. Soc. 2015, 162 (14), A2605-A2622.

(5) Lee, J.-S.; Tai Kim, S.; Cao, R.; Choi, N.-S.; Liu, M.; Lee, K. T.; Cho, J. Metal-Air Batteries with High Energy Density: Li-Air versus Zn-Air. Adv. Energy Mater. 2011, 1 (1), 34-50.

(6) Zhao, Q.; Yan, Z.; Chen, C.; Chen, J. Spinels: Controlled Preparation, Oxygen Reduction/Evolution Reaction Application, and Beyond. Chem. Rev. 2017, 117 (15), 10121-10211.

(7) Huang, Z.-F.; Wang, J.; Peng, Y.; Jung, C.-Y.; Fisher, A.; Wang, X. Design of Efficient Bifunctional Oxygen Reduction/Evolution Electrocatalyst: Recent Advances and Perspectives. Adv. Energy Mater. 2017, 7 (23), 1700544.

(8) Fu, J.; Cano, Z. P.; Park, M. G.; Yu, A.; Fowler, M.; Chen, Z. Electrically Rechargeable Zinc-Air Batteries: Progress, Challenges, and Perspectives. Adv. Mater. 2017, 29 (7), 1604685.

(9) Gewirth, A. A.; Varnell, J. A.; DiAscro, A. M. Nonprecious Metal Catalysts for Oxygen Reduction in Heterogeneous Aqueous Systems. Chem. Rev. 2018, 118 (5), 2313-2339.

(10) Shao, M.; Chang, Q.; Dodelet, J.-P.; Chenitz, R. Recent Advances in Electrocatalysts for Oxygen Reduction Reaction. Chem. Rev. 2016, 116 (6), 3594-3657.

(11) Suen, N.-T.; Hung, S.-F.; Quan, Q.; Zhang, N.; Xu, Y.-J.; Chen, H. M. Electrocatalysis for the Oxygen Evolution Reaction: Recent Development and Future Perspectives. Chem. Soc. Rev. 2017, 46 (2), 337-365.

(12) Manoj Kumar, B. V; Kim, Y.-W. Processing of Polysiloxane-Derived Porous Ceramics: A Review. Sci. Technol. Adv. Mater. 2010, 11 (4), 044303.

(13) Colombo, P.; Mera, G.; Riedel, R.; Sorarù, G. D. Polymer-Derived Ceramics: 40 Years of Research and Innovation in Advanced Ceramics. J. Am. Ceram. Soc. 2010, 93 (7), 1805-1837.

(14) Vakifahmetoglu, C.; Colombo, P.; Carturan, S. M.; Pippel, E.; Woltersdorf, J. Growth of One-Dimensional Nanostructures in Porous Polymer-Derived Ceramics by CatalystAssisted Pyrolysis. Part II: Cobalt Catalyst. J. Am. Ceram. Soc. 2010, 93 (11), 37093719.

(15) Terry, C. S.; Scheffler, F.; Torrey, J. D.; Bordia, R. K.; Scheffler, M. In Situ Carbon Nanotube Formation in Templated Pores of Polymer-Derived Ceramics. Adv. Eng. Mater. 2011, 13 (9), 906-912.

(16) Mantzel, N.; Rannabauer, S.; Bucharsky, E. C.; Schell, K. G.; Hoffmann, M. J.; Scheffler, M. A Novel Approach for the Processing of Advanced Polymer Derived 
Ceramics with Carbon Nanotubes with the Help of Pores. Adv. Eng. Mater. 2014, 16 (3), 295-300.

(17) Kaspar, J.; Storch, M.; Schitco, C.; Riedel, R.; Graczyk-Zajac, M. SiOC(N)/Hard Carbon Composite Anodes for Na-Ion Batteries: Influence of Morphology on the Electrochemical Properties. J. Electrochem. Soc. 2016, 163 (2), A156-A162.

(18) Idesaki, A.; Colombo, P. Synthesis of a Ni-Containing Porous SiOC Material From Polyphenylmethylsiloxane by a Direct Foaming Technique. Adv. Eng. Mater. 2012, 14 (12), 1116-1122.

(19) Zhang, H.; D’Angelo Nunes, P.; Wilhelm, M.; Rezwan, K. Hierarchically Ordered Micro/Meso/Macroporous Polymer-Derived Ceramic Monoliths Fabricated by FreezeCasting. J. Eur. Ceram. Soc. 2016, 36 (1), 51-58.

(20) Schlüter, F.; Wilhelm, M.; Rezwan, K. Surfactant Assisted Syntheses of Monolithic Hybrid Ceramics with Hierarchical Porosity. J. Eur. Ceram. Soc. 2015, 35 (11), 29632972.

(21) Schlüter, F.; Meyer, J.; Wilhelm, M.; Rezwan, K. Hierarchical Emulsion Based Hybrid Ceramics Synthesized with Different Siloxane Precursor and with Embedded Nickel Nanoparticles. Colloids Surfaces A Physicochem. Eng. Asp. 2016, 492, 160-169.

(22) Adam, M.; Kocanis, S.; Fey, T.; Wilhelm, M.; Grathwohl, G. Hierarchically Ordered Foams Derived from Polysiloxanes with Catalytically Active Coatings. J. Eur. Ceram. Soc. 2014, 34 (7), 1715-1725.

(23) David, L.; Bhandavat, R.; Barrera, U.; Singh, G. Silicon Oxycarbide Glass-Graphene Composite Paper Electrode for Long-Cycle Lithium-Ion Batteries. Nat. Commun. 2016, 7, 10998.

(24) Wan, L.; Wang, J.; Sun, Y.; Feng, C.; Li, K. Polybenzoxazine-Based NitrogenContaining Porous Carbons for High-Performance Supercapacitor Electrodes and Carbon Dioxide Capture. RSC Adv. 2015, 5 (7), 5331-5342.

(25) Schubert, M.; Wilhelm, M.; Bragulla, S.; Sun, C.; Neumann, S.; Gesing, T. M.; Pfeifer, P.; Rezwan, K.; Bäumer, M. The Influence of the Pyrolysis Temperature on the Material Properties of Cobalt and Nickel Containing Precursor Derived Ceramics and Their Catalytic Use for $\mathrm{CO}_{2}$ Methanation and Fischer-Tropsch Synthesis. Catal. Letters 2017, 147 (2), 472-482.

(26) Pradeep, V. S.; Graczyk-Zajac, M.; Riedel, R.; Soraru, G. D. New Insights in to the Lithium Storage Mechanism in Polymer Derived SiOC Anode Materials. Electrochim. Acta 2014, 119, 78-85.

(27) Kolathodi, M. S.; David, L.; Abass, M. A.; Singh, G. Polysiloxane-Functionalized Graphene Oxide Paper: Pyrolysis and Performance as a Li-Ion Battery and Supercapacitor Electrode. RSC Adv. 2016, 6 (78), 74323-74331.

(28) Prenzel, T.; Wilhelm, M.; Rezwan, K. Tailoring Amine Functionalized Hybrid Ceramics to Control $\mathrm{CO}_{2}$ Adsorption. Chem. Eng. J. 2014, 235, 198-206.

(29) David, L.; Bhandavat, R.; Barrera, U.; Singh, G. Polymer-Derived Ceramic Functionalized $\mathrm{MoS}_{2}$ Composite Paper as a Stable Lithium-Ion Battery Electrode. Sci. Rep. 2015, 5 (1), 9792.

(30) Harms, C.; Adam, M.; Soliman, K. A.; Wilhelm, M.; Kibler, L. A.; Jacob, T.; Grathwohl, G. New Electrocatalysts with Pyrolyzed Siloxane Matrix. Electrocatalysis 
2014, 5 (3), 301-309.

(31) Moni, P.; Chaves, W. F.; Wilhelm, M.; Rezwan, K. Polysiloxane Microspheres Encapsulated in Carbon Allotropes: A Promising Material for Supercapacitor and Carbon Dioxide Capture. J. Colloid Interface Sci. 2019, 542, 91-101.

(32) Canuto de Almeida e Silva, T.; Mooste, M.; Kibena-Põldsepp, E.; Matisen, L.; Merisalu, M.; Kook, M.; Sammelselg, V.; Tammeveski, K.; Wilhelm, M.; Rezwan, K. Polymer-Derived $\mathrm{Co} / \mathrm{Ni}-\mathrm{SiOC}(\mathrm{N})$ Ceramic Electrocatalysts for Oxygen Reduction Reaction in Fuel Cells. Catal. Sci. Technol. 2019, 9 (3), 854-866.

(33) Abinaya, S.; Moni, P.; Parthiban, V.; Sahu, A. K.; Wilhelm, M. Metal Silicide Nanosphere Decorated Carbon-Rich Polymer-Derived Ceramics: Bifunctional Electrocatalysts towards Oxygen and Their Application in Anion Exchange Membrane Fuel Cells. ChemElectroChem 2019, 6, 3268.

(34) Han, S. A.; Lee, J.; Shim, K.; Lin, J.; Shahabuddin, M.; Lee, J.-W.; Kim, S.-W.; Park, M.-S.; Kim, J. H. Strategically Designed Zeolitic Imidazolate Frameworks for Controlling the Degree of Graphitization. Bull. Chem. Soc. Jpn. 2018, 91 (10), 14741480.

(35) Chen, X.; Zhao, A.; Shao, Z.; Li, C.; Williams, C. T.; Liang, C. Synthesis and Catalytic Properties for Phenylacetylene Hydrogenation of Silicide Modified Nickel Catalysts. $J$. Phys. Chem. C 2010, 114 (39), 16525-16533.

(36) Chen, X.; Li, M.; Guan, J.; Wang, X.; Williams, C. T.; Liang, C. Nickel-Silicon Intermetallics with Enhanced Selectivity in Hydrogenation Reactions of Cinnamaldehyde and Phenylacetylene. Ind. Eng. Chem. Res. 2012, 51 (9), 3604-3611.

(37) Chen, X.; Zhang, M.; Yang, K.; Williams, C. T.; Liang, C. Raney Ni-Si Catalysts for Selective Hydrogenation of Highly Concentrated 2-Butyne-1,4-Diol to 2-Butene-1,4Diol. Catal. Letters 2014, 144 (7), 1118-1126.

(38) Chen, X.; Jin, J.; Sha, G.; Li, C.; Zhang, B.; Su, D.; Williams, C. T.; Liang, C. SiliconNickel Intermetallic Compounds Supported on Silica as a Highly Efficient Catalyst for CO Methanation. Catal. Sci. Technol. 2014, 4 (1), 53-61.

(39) Chen, X.; Liu, X.; Wang, L.; Li, M.; Williams, C. T.; Liang, C. High Sulfur Tolerance of Ni-Si Intermetallics as Hydrodesulfurization Catalysts. RSC Adv. 2013, 3 (6), 17281731.

(40) Ryabchuk, P.; Agostini, G.; Pohl, M.; Lund, H.; Agapova, A.; Junge, H.; Junge, K.; Beller, M. Intermetallic Nickel Silicide Nanocatalyst-A Non-Noble Metal-Based General Hydrogenation Catalyst. Sci. Adv. 2018, 4 (6), eaat0761.

(41) Arunchander, A.; Peera, S. G.; Panda, S. K.; Chellammal, S.; Sahu, A. K. Simultaneous Co-Doping of $\mathrm{N}$ and $\mathrm{S}$ by a Facile in-Situ Polymerization of 6- N,N -Dibutylamine1,3,5-Triazine-2,4-Dithiol on Graphene Framework: An Efficient and Durable Oxygen Reduction Catalyst in Alkaline Medium. Carbon 2017, 118, 531-544.

(42) Arunchander, A.; Peera, S. G.; Sahu, A. K. Synthesis of Flower-like Molybdenum Sulfide/Graphene Hybrid as an Efficient Oxygen Reduction Electrocatalyst for Anion Exchange Membrane Fuel Cells. J. Power Sources 2017, 353, 104-114.

(43) Scheffler, M.; Greil, P.; Berger, A.; Pippel, E.; Woltersdorf, J. Nickel-Catalyzed in Situ Formation of Carbon Nanotubes and Turbostratic Carbon in Polymer-Derived Ceramics. Mater. Chem. Phys. 2004, 84 (1), 131-139. 
(44) Dasgupta, K.; Sathiyamoorthy, D. Disordered Carbon-Its Preparation, Structure, and Characterisation. Mater. Sci. Technol. 2003, 19 (8), 995-1002.

(45) Sasikumar, P. V. W.; Blugan, G.; Casati, N.; Kakkava, E.; Panusa, G.; Psaltis, D.; Kuebler, Polymer Derived Silicon Oxycarbide Ceramic Monoliths: Microstructure Development and Associated Materials Properties. Ceram. Int. 2018, 4 (1), 2096120967.

(46) Yu, M.; Picot, O. T.; Saunders, T. G.; Dlouhý, I.; Feng, J.; Titirici, M.-M.; Mahajan, A.; Reece, M. J. Graphene-Reinforced Silicon Oxycarbide Composites Prepared by Phase Transfer. Carbon 2018, 139, 813-823.

(47) Ionescu, E.; Francis, A.; Riedel, R. Dispersion Assessment and Studies on AC Percolative Conductivity in Polymer-Derived Si-C-N/CNT Ceramic Nanocomposites. J. Mater. Sci. 2009, 44 (8), 2055-2062.

(48) Roth, F.; Schmerbauch, C.; Ionescu, E.; Nicoloso, N.; Guillon, O.; Riedel, R. HighTemperature Piezoresistive C/SiOC Sensors. J. Sensors Sens. Syst. 2015, 4 (1), 133136.

(49) Seifollahi Bazarjani, M.; Kleebe, H.-J.; Müller, M. M.; Fasel, C.; Baghaie Yazdi, M.; Gurlo, A.; Riedel, R. Nanoporous Silicon Oxycarbonitride Ceramics Derived from Polysilazanes In Situ Modified with Nickel Nanoparticles. Chem. Mater. 2011, 23 (18), 4112-4123.

(50) Peng, Y.; Wang, K.; Yu, M.; Li, A.; Bordia, R. K. An Optimized Process for in Situ Formation of Multi-Walled Carbon Nanotubes in Templated Pores of Polymer-Derived Silicon Oxycarbide. Ceram. Int. 2017, 43 (4), 3854-3860.

(51) Reichert, D.; Bockhorn, H.; Kureti, S. Study of the Reaction of $\mathrm{NO}_{\mathrm{x}}$ and Soot on $\mathrm{Fe}_{2} \mathrm{O}_{3}$ Catalyst in Excess of $\mathrm{O}_{2}$. Appl. Catal. B Environ. 2008, 80 (3-4), 248-259.

(52) Moni, P.; Wilhelm, M.; Rezwan, K. The Influence of Carbon Nanotubes and Graphene Oxide Sheets on the Morphology, Porosity, Surface Characteristics and Thermal and Electrical Properties of Polysiloxane Derived Ceramics. RSC Adv. 2017, 7 (60), 3755937567.

(53) Prabu, M.; Selvasekarapandian, S.; Reddy, M. V.; Chowdari, B. V. R. Impedance Studies on the 5-V Cathode Material, $\mathrm{LiCoPO}_{4}$. J. Solid State Electrochem. 2012, 16 (5), 1833-1839.

(54) Prabu, M.; Ramakrishnan, P.; Nara, H.; Momma, T.; Osaka, T.; Shanmugam, S. ZincAir Battery: Understanding the Structure and Morphology Changes of GrapheneSupported $\mathrm{CoMn}_{2} \mathrm{O}_{4}$ Bifunctional Catalysts Under Practical Rechargeable Conditions. ACS Appl. Mater. Interfaces 2014, 6 (19), 16545-16555.

(55) Prabu, M.; Ramakrishnan, P.; Ganesan, P.; Manthiram, A.; Shanmugam, S. $\mathrm{LaTi}_{0.65} \mathrm{Fe}_{0.35} \mathrm{O}_{3-\delta}$ Nanoparticle-Decorated Nitrogen-Doped Carbon Nanorods as an Advanced Hierarchical Air Electrode for Rechargeable Metal-Air Batteries. Nano Energy 2015, 15, 92-103.

(56) Prabu, M.; Ketpang, K.; Shanmugam, S. Hierarchical Nanostructured $\mathrm{NiCo}_{2} \mathrm{O}_{4}$ as an Efficient Bifunctional Non-Precious Metal Catalyst for Rechargeable Zinc-Air Batteries. Nanoscale 2014, 6 (6), 3173-3181.

(57) Arunchander, A.; Peera, S. G.; Giridhar, V. V.; Sahu, A. K. Synthesis of Cobalt Sulfide-Graphene as an Efficient Oxygen Reduction Catalyst in Alkaline Medium and 
Its Application in Anion Exchange Membrane Fuel Cells. J. Electrochem. Soc. 2017, 164 (2), F71-F80.

(58) Arunchander, A.; Peera, S. G.; Sahu, A. K. Self-Assembled Manganese Sulfide Nanostructures on Graphene as an Oxygen Reduction Catalyst for Anion Exchange Membrane Fuel Cells. ChemElectroChem 2017, 4 (6), 1544-1553.

(59) Liu, W., Zhang, J., Bai, Z., Jiang, G., Li, M., Feng, K., Yang, L., Ding, Y., Yu, T., Chen, Z., Yu, A.,Controllable Urchin-Like $\mathrm{NiCo}_{2} \mathrm{~S}_{4}$ Microsphere Synergized with Sulfur-Doped Graphene as Bifunctional Catalyst for Superior Rechargeable Zn-Air Battery. Adv. Funct. Mater. 2018, 28 (11), 1706675.

(60) Jiang, Y., Deng, Y.-P., Fu, J., Lee, D. U., Liang, R., Cano, Z. P., Liu, Y., Bai, Z., Hwang, S., Yang, L., Su, D., Chu, W., Chen, Z., Interpenetrating Triphase CobaltBased Nanocomposites as Efficient Bifunctional Oxygen Electrocatalysts for LongLasting Rechargeable Zn-Air Batteries. Adv. Energy Mater. 2018, 8 (15), 1702900.

(61) Lee, J.-S.; Nam, G.; Sun, J.; Higashi, S.; Lee, H.-W.; Lee, S.; Chen, W.; Cui, Y.; Cho, J. Composites of a Prussian Blue Analogue and Gelatin-Derived Nitrogen-Doped Carbon-Supported Porous Spinel Oxides as Electrocatalysts for a Zn-Air Battery. $A d v$. Energy Mater. 2016, 6 (22), 1601052.

(62) Hu, S.; Han, T.; Lin, C.; Xiang, W.; Zhao, Y.; Gao, P.; Du, F.; Li, X.; Sun, Y. Enhanced Electrocatalysis via 3D Graphene Aerogel Engineered with a Silver Nanowire Network for Ultrahigh-Rate Zinc-Air Batteries. Adv. Funct. Mater. 2017, 27 (18), 1700041. 

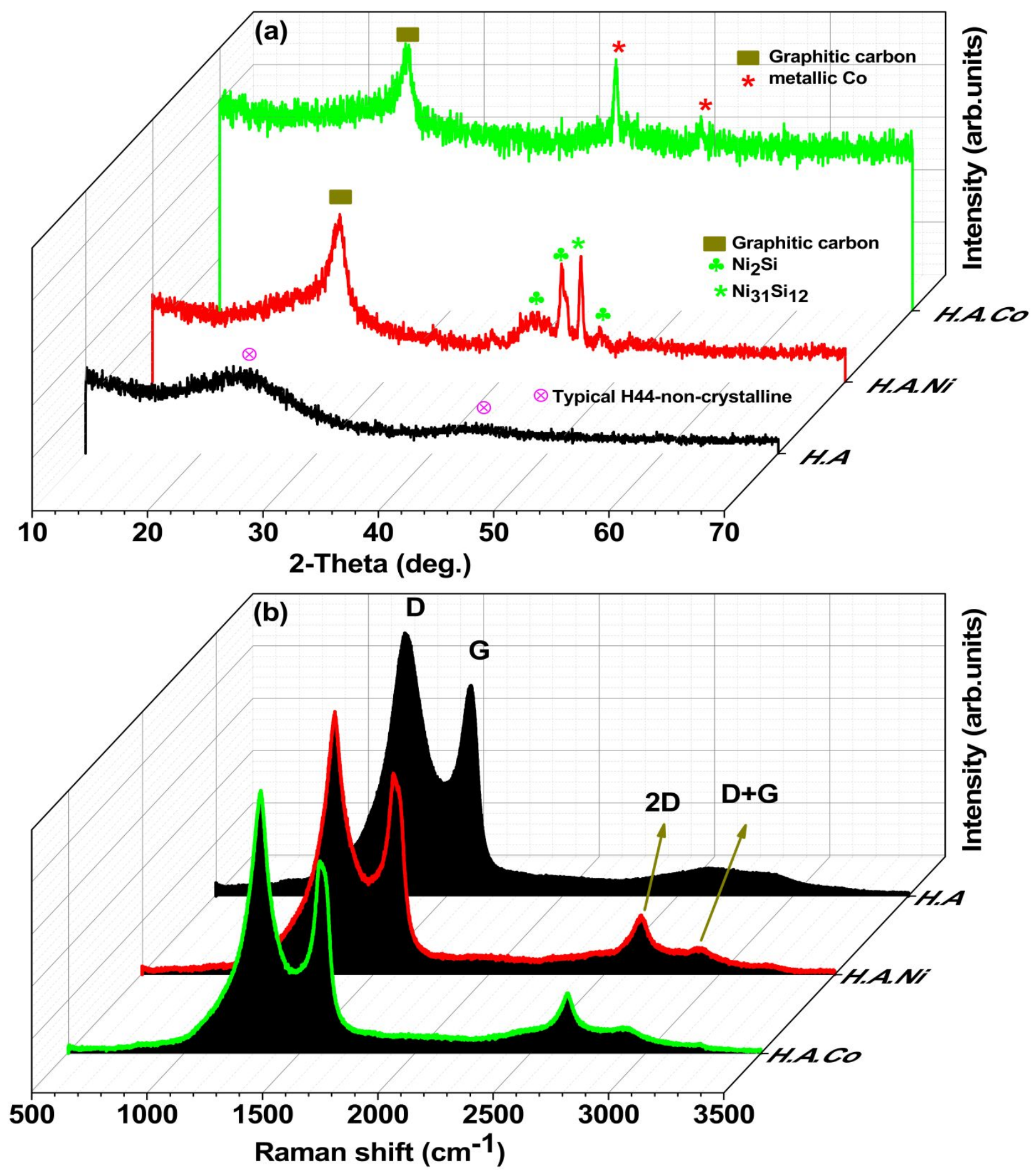

Fig. 1 (a) XRD; and (b) Raman patterns of ceramic monoliths. H.A; H.A.Ni; and. H.A.Co 

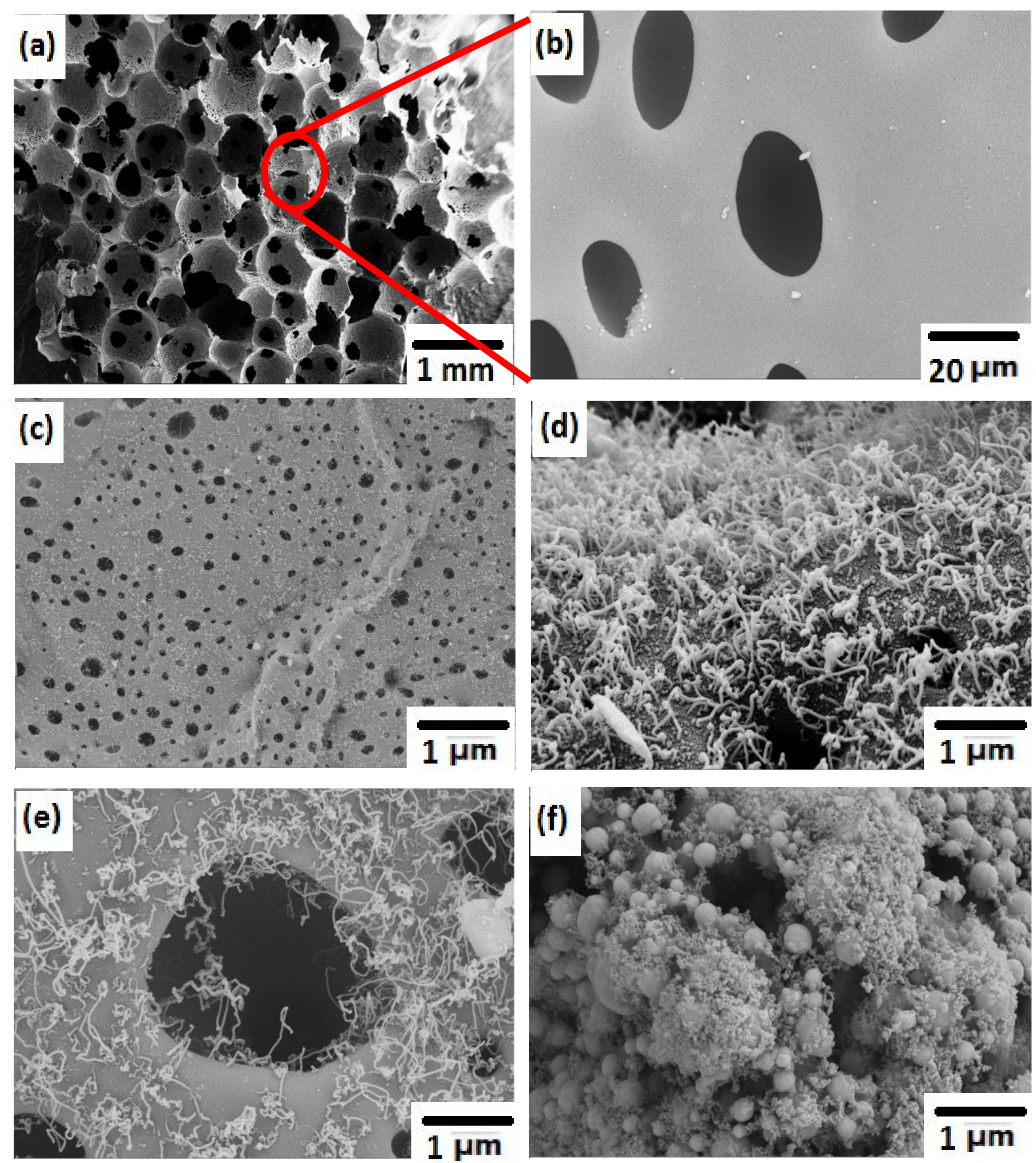

Fig. 2 FESEM images of ceramic monoliths. (a-b) H.A; (c-d) H.A.Ni; (e) H.A.Co; and (f) H.A.Pt 

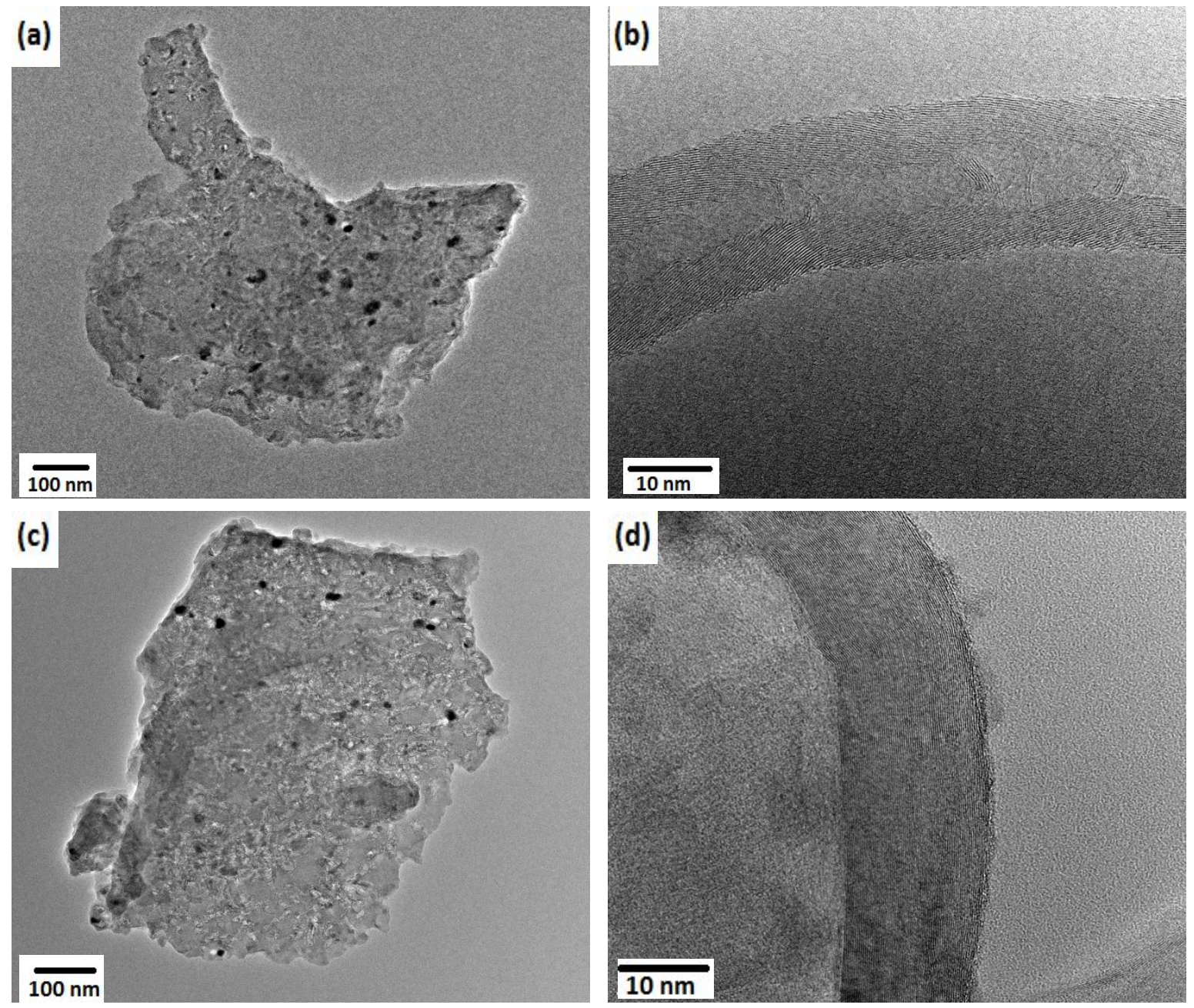

Fig. 3 FETEM images showing the nanoparticle distribution and CNT formation within the ceramics. (a, b) H.A.Ni, and (c, d) H.A.Co 

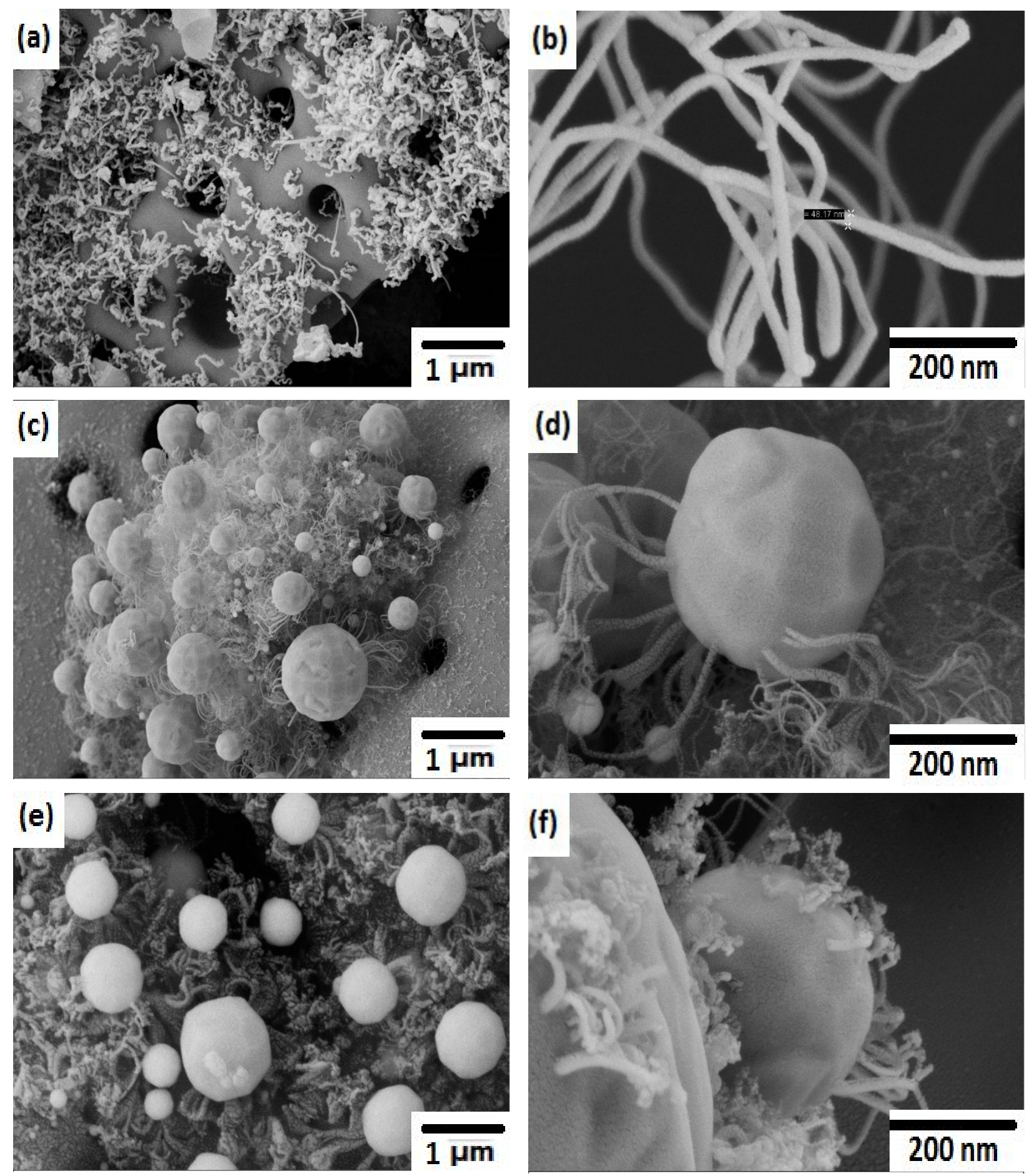

Fig. 4 FESEM images of ceramic monoliths (a, b) H.A.Ni.Co; (c, d) H.A.Ni.Pt; and (e, f) H.A.Co.Pt 

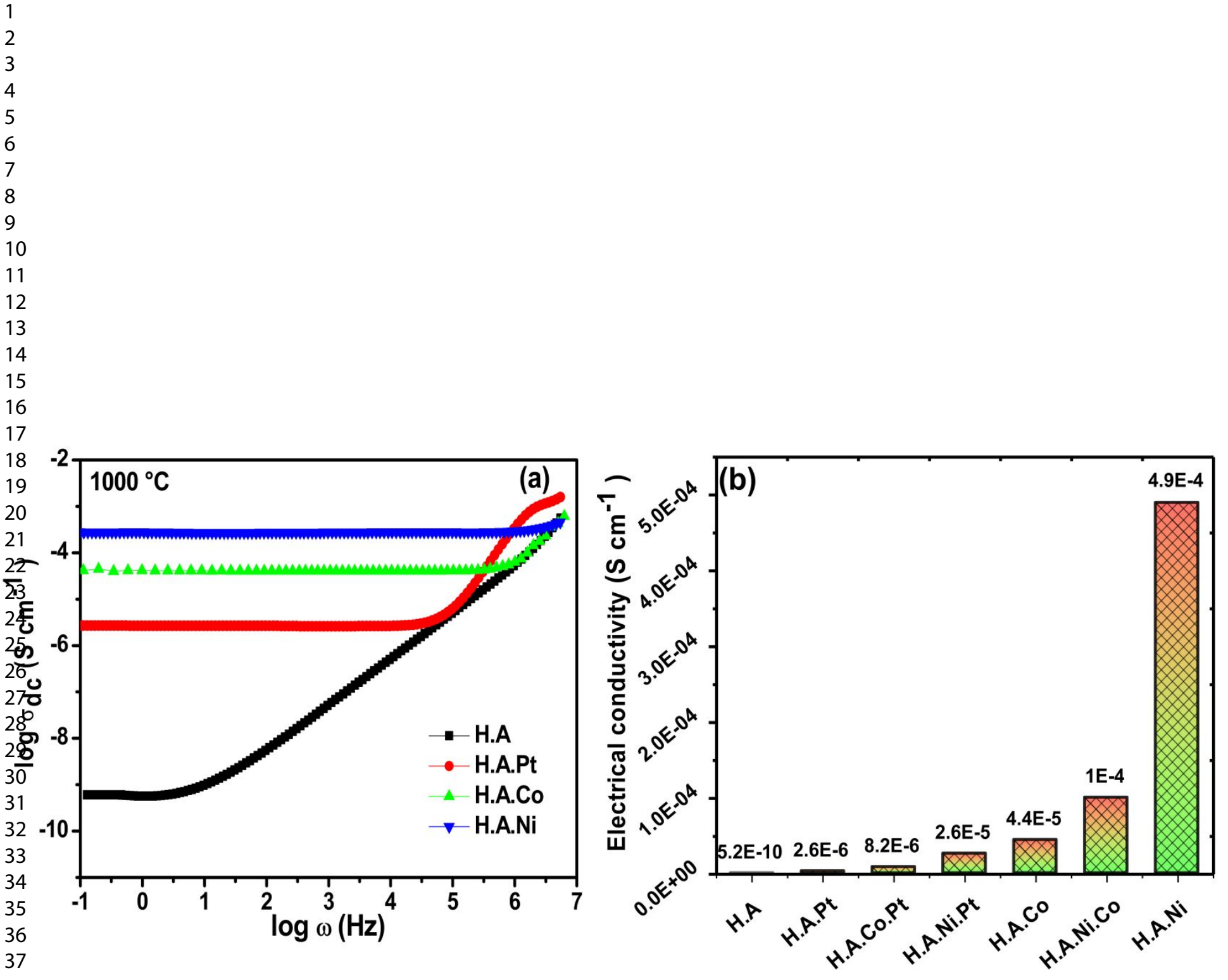

Fig. 5 (a) Conductance spectra of ceramic composite recorded at room temperature; and (b) Corresponding room temperature DC conductivity 

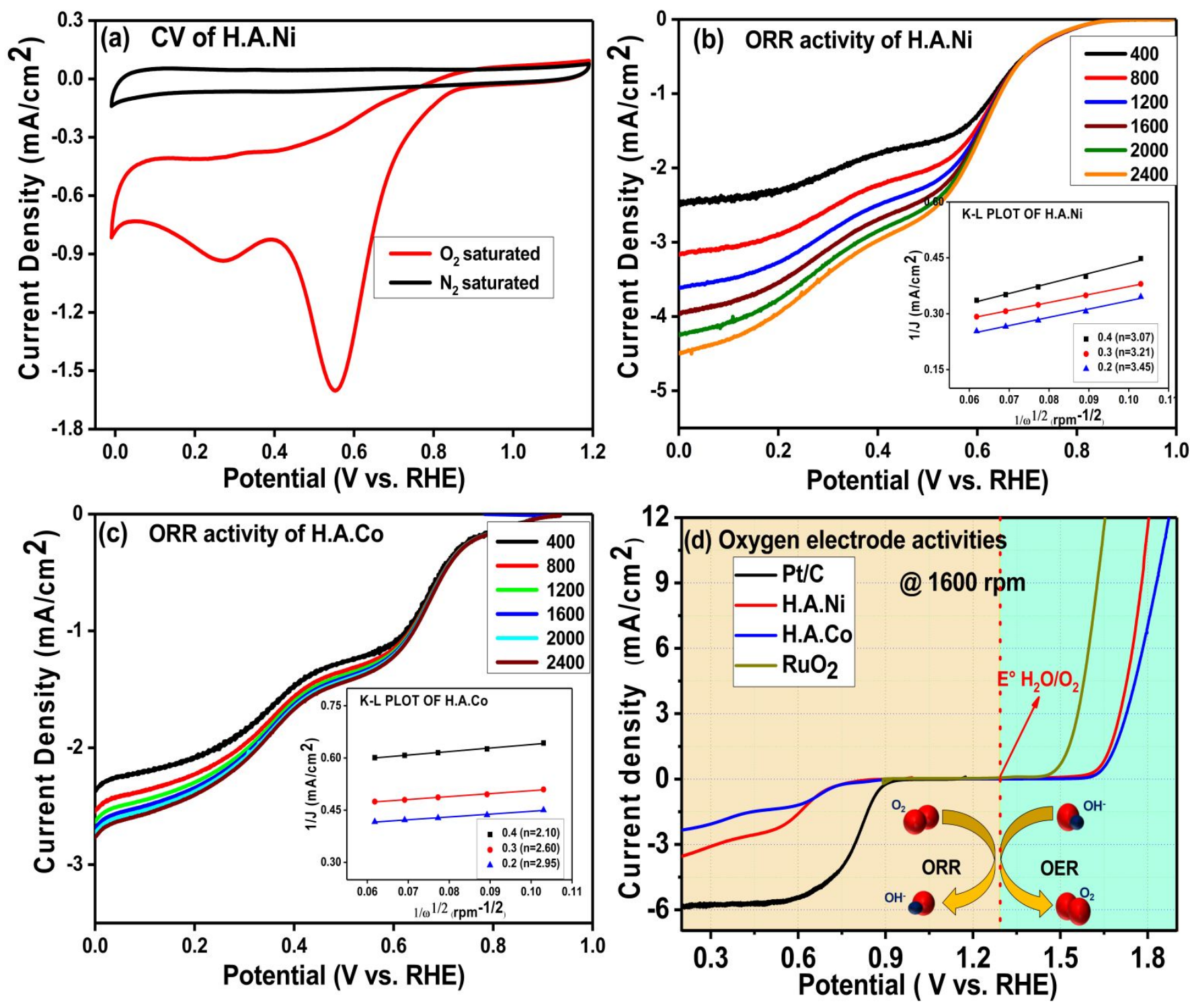

Fig. 6 Electrocatalytic activities of metal-containing ceramics in $0.1 \mathrm{M} \mathrm{KOH}$ electrolyte solution at a scan rate of $5 \mathrm{mV} \mathrm{s}^{-1}$. (a) $\mathrm{CV}$ for H.A.Ni. Oxygen reduction polarization for (b) H.A.Ni; (c) H.A.Co at various rotation; insets show K-L plots, (d) Oxygen electrode activity of metal-containing ceramics and compared with $\mathrm{Pt} / \mathrm{C}$ and $\mathrm{Ru} \mathrm{O}_{2}$ at $1600 \mathrm{rpm}$ 


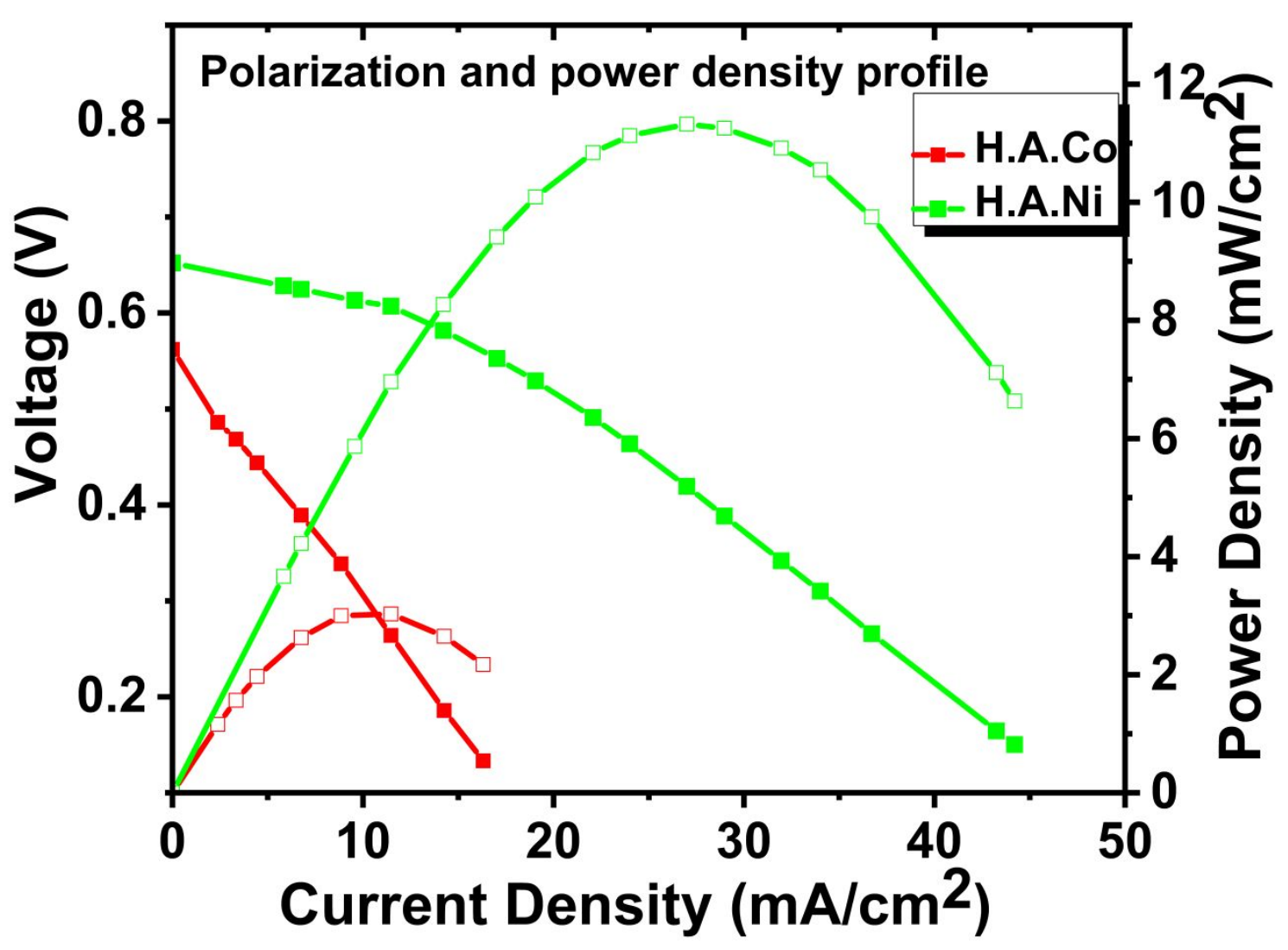

Fig. 7 Polarization and power density curves of AEMFC comprising H.A.Ni and H.A.Co as cathode catalysts in $\mathrm{H}_{2} / \mathrm{O}_{2}$ feeds at $30{ }^{\circ} \mathrm{C}$ and ambient pressure under $100 \% \mathrm{RH}$ 

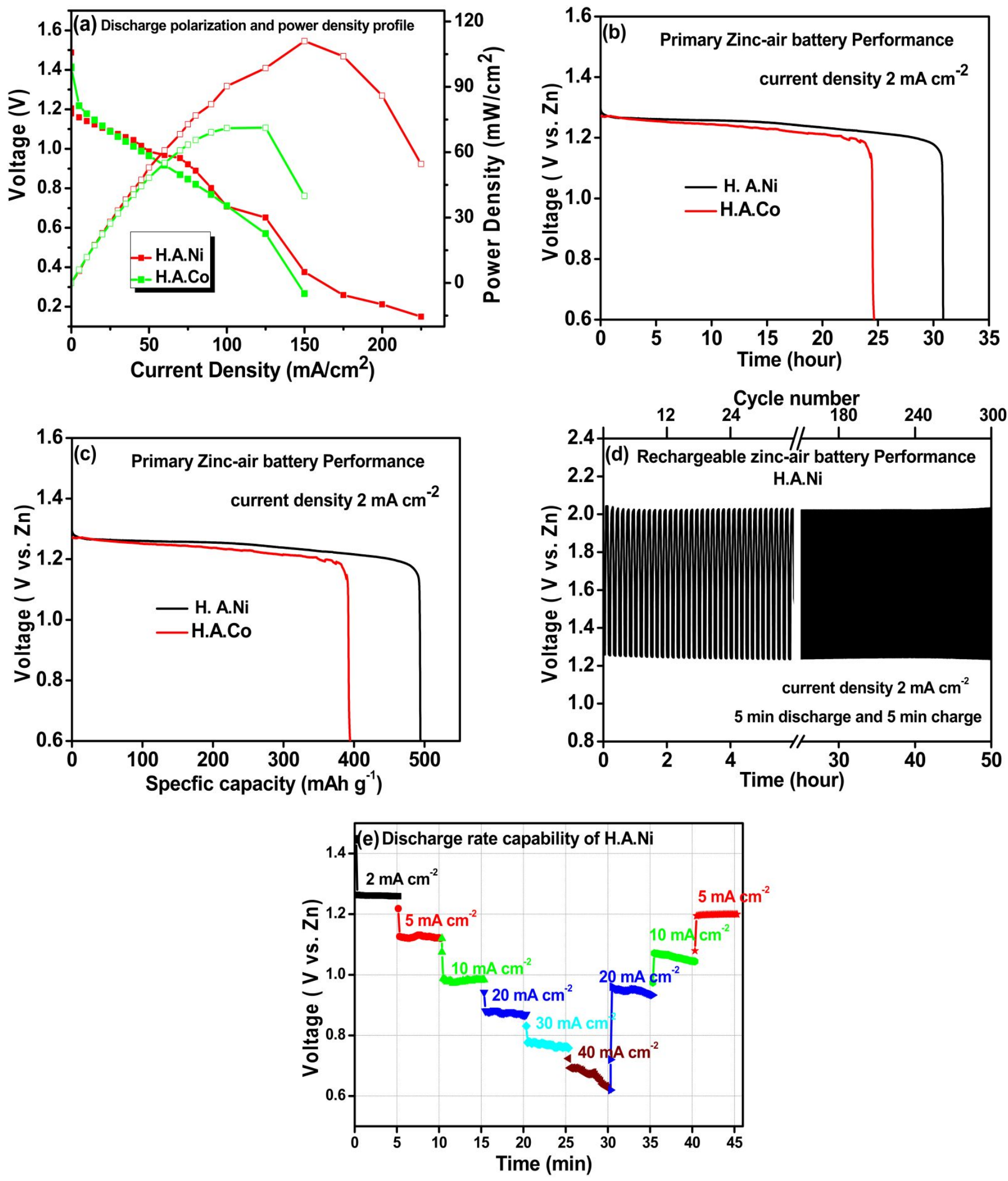

Fig. 8 ZAB performance of metal-containing ceramics by consuming open air. (a) Polarization and power density curves; $(b, c)$ Primary battery performance; (d) Rechargeable battery performance; (e) Discharge profiles from low current to high current densities 


\section{GRAPHICAL ABSTRACT}

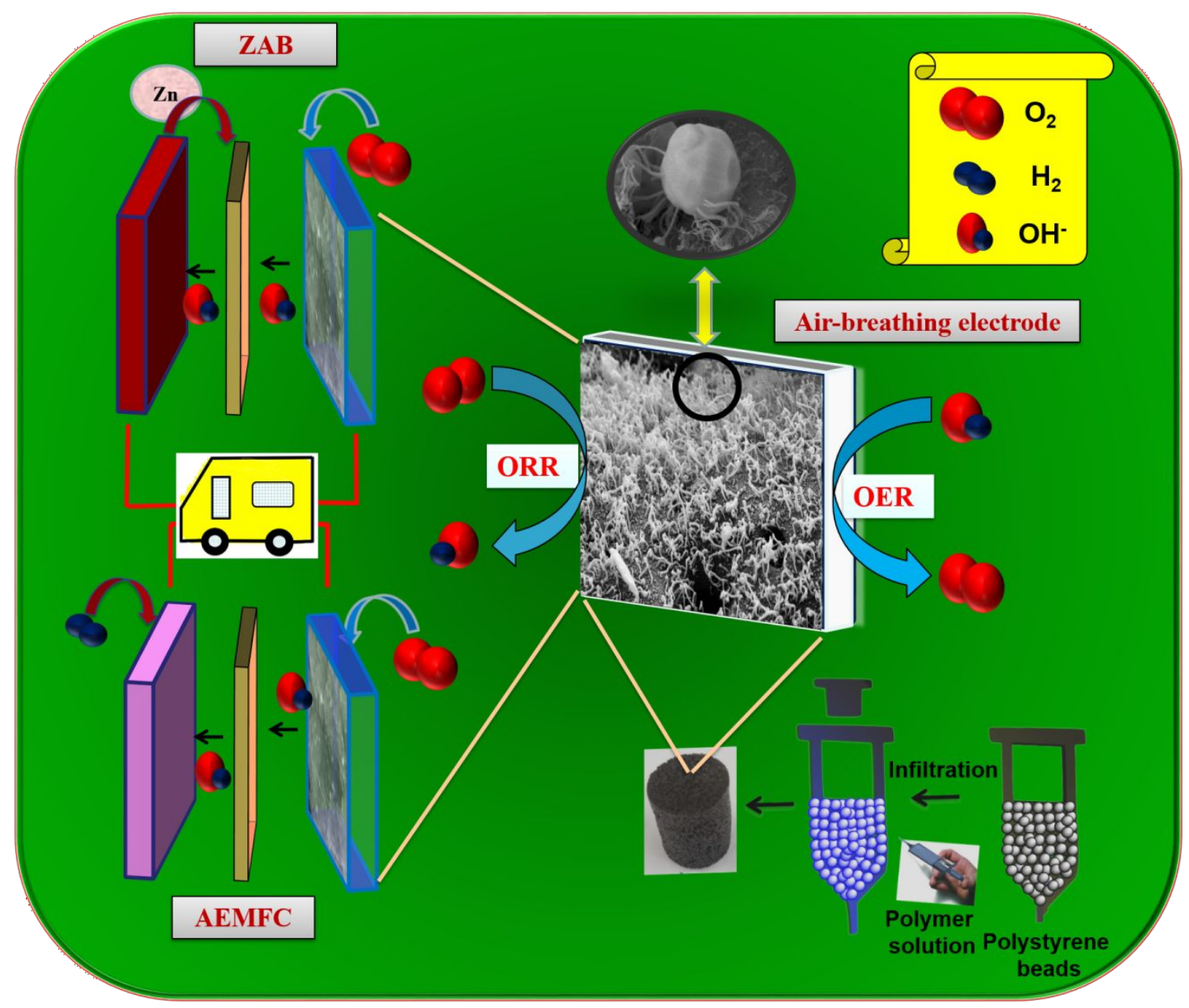

